\title{
The effect of varying rest intervals following the development of oscillation during unilateral amygdaloid stimulation
}

\author{
JOHN GAITO \\ York University, 4700 Keele Street, Downsview MSJ 1P3, Ontario, Canada
}

\begin{abstract}
Fifteen rats showing prominent oscillation patterns in latency during sequential alternation of unilateral amygdaloid stimulation were separated into three groups of five rats each. Group 1 rats were rested for 1 month prior to continuing sequential alternations. Groups 2 and 3 rats were rested for 3 months and 6 months, respectively. In spite of these rest intervals, most rats continued to show the same oscillation pattern as that before the rest period.
\end{abstract}

Previous research indicated an "oscillation effect" when a sequence of alternating unilateral stimulations of the amygdala were utilized (Gaito, 1976a). This oscillation usually consisted of low values for the amygdala first stimulated (primary site) and high values for the contralateral amygdala (secondary site). The effect was most prominent in latency data.

Bilateral stimulation prior to, or after, the development of oscillation had no disruptive effect on the oscil-lation tendency (Gaito, 1976b). Likewise, the tendency persisted with 1, 3, or 6 trials per day (Gaito, 1976c) and 1, 6, and 12 convulsions per phase (Gaito, 1976d). In the present study, the effects of rest intervals of varying duration were investigated to determine if the tendency decays with time.

\section{METHOD}

Male Wistar rats (approximately 135 days of age) were implanted bilaterally with bipolar electrodes in the amygdala. The brain coordinates for electrode implantation were the same as in previous experiments: $.5 \mathrm{~mm}$ posterior to bregma, $4.5 \mathrm{~mm}$ from midline, $8.5 \mathrm{~mm}$ from skull. Seven or more days after surgery, brain stimulation began. Each rat was stimulated for $30 \mathrm{sec}$ with a $60-\mathrm{Hz}$ wave of 100 microA (peak to peak), using a Iafayette stimulator until six convulsions resulted. There were three trials per day, with $1 \mathrm{~h}$ between trials. On the day after the sixth convulsion, stimulation began at the secondary site and continued until six convulsions occurred. Then stimulation at the primary site was again instituted, etc. This sequential alternation of unilateral stimulation was continued for 10 phases. Fifteen rats showing prominent oscillation were identified and assigned to three groups of five. In Group 1 the rats were rested for approximately 1 month and then stimulated unilaterally over 10 alternating phases. Similar procedures were followed with Group 2 rats after a 3-month rest and with Group 3 rats following a 6-month rest.

\section{RESULTS}

The responses of the 15 rats are shown in Table 1. In jeneral, none of the rest periods had an effect; the behavioral response was the same for both prerest and postrest stimulation for most rats. All rats oscillated in both
Table 1

Latency (L) and Criterion (C) Responses for the 15 Subjects

\begin{tabular}{|c|c|c|c|}
\hline \multicolumn{2}{|c|}{ Prerest } & \multicolumn{2}{|c|}{ Postrest } \\
\hline $\mathrm{L}$ & $\mathrm{C}$ & $\mathbf{L}$ & $\mathrm{C}$ \\
\hline \multicolumn{4}{|c|}{ 1-Month Group } \\
\hline PO & SO & SO* & SO \\
\hline SO & NO & SO & NO \\
\hline PO & NO & PO & $\mathrm{SO}^{* *}$ \\
\hline PO & PO & PO & $\mathrm{NO} \dagger$ \\
\hline PO & NO & PO & NO \\
\hline \multicolumn{4}{|c|}{ 3-Months Group } \\
\hline PO & PO & PO & $\mathrm{NO} \dagger$ \\
\hline SO & NO & SO & NO \\
\hline PO & NO & PO & NO \\
\hline PO & NO & PO & PO** \\
\hline SO & NO & SO & $\mathrm{PO}^{* *}$ \\
\hline \multicolumn{4}{|c|}{ 6-Months Group } \\
\hline PO & NO & PO & NO \\
\hline PO & NO & PO & NO \\
\hline PO & NO & PO & NO \\
\hline PO & NO & PO & NO \\
\hline PO & NO & SO* & NO \\
\hline
\end{tabular}

Note-PO, primary oscillation; $S O$, secondary oscillation; $N O$, nonoscillation. $\quad{ }^{*}$ Reversed oscillation pattern **Initiated oscillation tDisrupted oscillation

sessions in latency data; however, two rats changed from primary to secondary oscillation. In the criterion measure, most rats did not oscillate in either the prerest or postrest sessions. During the postrest session, two rats which had oscillated previously terminated oscillation and three rats began to oscillate.

Typical oscillation data are presented in Table 2 for the last four phases of the prerest session and the 10 postrest phases.

\section{DISCUSSION}

These results are consistent with previous findings (Gaito, $1976 \mathrm{a}, \mathrm{b}, \mathrm{c}, \mathrm{d})$ which demonstrated the oscillation tendency and indicate the authenticity of the oscillation effect. This tendency appears to be a prominent feature of unilateral sequential alter- 
Table 2

Typical Oscillation for Latency (in Seconds)

\begin{tabular}{|c|c|c|c|c|c|c|c|c|c|c|c|c|c|c|c|}
\hline \multirow[b]{2}{*}{ Rat } & \multirow[b]{2}{*}{ Group } & \multicolumn{4}{|c|}{ Last Four Prerest Phases } & \multicolumn{10}{|c|}{ Postrest Phases } \\
\hline & & 1 & 2 & 3 & 4 & 1 & 2 & 3 & 4 & 5 & 6 & 7 & 8 & 9 & 10 \\
\hline 11 & 1 & 4.5 & 18.5 & 5.3 & 14.2 & 7.7 & 14.0 & 6.3 & 18.3 & 5.3 & 17.7 & 6.3 & 17.5 & 12.2 & 16.0 \\
\hline 10 & 2 & 1.0 & 7.8 & 2.2 & 7.3 & 5.8 & 6.8 & 3.3 & 6.2 & 2.8 & 7.2 & 1.3 & 6.2 & 1.2 & 4.8 \\
\hline 18 & 3 & 2.7 & 1.0 & 1.7 & 1.0 & 2.8 & 10.3 & 2.8 & 6.2 & 2.0 & 5.0 & 1.0 & 4.8 & 1.2 & 3.0 \\
\hline
\end{tabular}

nations and is not due to chance aspects or to poorly placed electrodes in one of the two sites (Gaito, 1976a, b). In the first study (Gaito, 1976a), histological analyses were conducted on most of the rats. Placement of electrodes appeared to be unrelated to oscillation or nonoscillation behavior. For example, some rats with electrodes in the same amygdaloid nucleus on both sides showed oscillation in both latency and criterion data, some oscillated in only one of the two, and some did not oscillate in either dependent variable. Likewise, if one electrode was in the amygdala and the other was outside, oscillation resulted but not in the fashion expected. For example, one rat required an extreme number of trials (50) to achieve the criterion of $6 \mathrm{CCs}$ for the first side stimulated; the electrode was in the caudate putamen/globus pallidus area. Even though the electrode was not in the amygdala and the kindling rate was slow, latency was lower on this side than on the contralateral side (electrode in the amygdala), and primary oscillation resulted. In this case, if the misplaced electrode were the basis for the oscillation effect, latency should have been lower on the contralateral side (secondary oscillation). Furthermore, results by McIntyre (1975) reporting primary oscillation over three phases of sequential alternation in latency data also suggest the authenticity of the oscillation tendency.

The fact that 1,3 , and 6 months of nonstimulation had little or no effect on the oscillation tendency might suggest that the mechanism for oscillation is of a long-term nature. However, it is possible that the basis for this tendency is of short-term nature and is generated during each phase anew. The behavior of the rats which changed from primary to secondary oscillation suggest this possibility.
One possible means of evaluating whether the mechanism of oscillation is of short- or long-term nature would be to separate each phase by a rest period, e.g., 14 days. McIntyre and Goddard (1973) found that interference of one amygdala with the contralateral one dissipated by 14 days during three-phase sequential alternation.

\section{REFERENCES}

GAIto, J. An oscillation effect during sequential alternations of unilateral amygdaloid stimulations within the kindling paradigm. Physiological Psychology, 1976, in press. (a)

GaITo, J. The effect of bilateral stimulation during sequential alternation of unilateral amygdaloid stimulation. Bulletin of the Psychonomic Society, 1976, 4, 355-357. (b)

GaIto, J. The effect of number of trials per day during unilateral amygdaloid stimulation. Bulletin of the Psychonomic Society, 1976, 4, 403-404. (c)

GaITo. J. The effect of number of convulsions per phase on the oscillation tendency. Bulletin of the Psychonomic Society, 1976, in press. (d)

MCINTYRE, D. C. Split-brain rat: Transfer and interference of kindled amygdala convulsions. Canadian Journal of Neurological Sciences, 1975, 2, 429-437.

MCINTYRE, D. C., \& GODDARD, G. V. Transfer, interference and spontaneous recovery of convulsions kindled from the rat amygdala. Electroencephalography and Clinical Neurophysiology, 1973, 35, 533-543.

(Received for publication July 23, 1976.) 